\title{
Prosthetic incisional hernioplasty
}

\author{
V. Wiwanitkit
}

Received: 10 August 2010/Accepted: 3 October 2010/Published online: 13 October 2010

(C) Springer-Verlag 2010

\section{Dear Editor,}

I read the recent publication on prosthetic incisional hernioplasty by Abdollahi et al. [1]. The authors concluded that "the prosthetic incisional hernioplasty approaches, especially the Rives-Stoppa method, yielded excellent long-term results, with minimal morbidity in patients and large primary or recurrent incisional repair." Indeed, there are some current reports on prosthetic incisional hernioplasty. Mehrabi et al. [2] reported a cross-publication in World J Surg that "The Rives-Stoppa repair of complex ventral incisional hernia using a Mersilene prosthesis is a safe and durable technique with excellent long-term results and minimal serious morbidity, with an overall recurrence rate in the present series of $1.1 \%$." The recurrence rate at present is higher compared to that reported by the crossauthors in that paper [2]. Hence, this might imply that the actual recurrence rate might be higher than that which is presented if larger surgeries are performed. In addition, some serious complications such as seroma and wound infections should still be kept in mind [3].

\section{References}

1. Abdollahi A, Maddah GH, Mehrabi BM, Jangjoo A, Forghani MN, Sharbaf N (2010) Prosthetic incisional hernioplasty: clinical experience with 354 cases. Hernia [Epub ahead of print]

2. Mehrabi M, Jangjoo A, Tavoosi H, Kahrom M, Kahrom H (2010) Long-term outcome of Rives-Stoppa technique in complex ventral incisional hernia repair. World J Surg 34(7):1696-1701

3. Bauer JJ, Harris MT, Gorfine SR, Kreel I (2002) Rives-Stoppa procedure for repair of large incisional hernias: experience with 57 patients. Hernia 6(3):120-123

V. Wiwanitkit ( $\square)$

Wiwanitkit House, Bangkhae, Bangkok 10160, Thailand

e-mail:wviroj@yahoo.com 